\title{
ASSISTANCE TO THE POOR IN A FEDERAL SYSTEM
}

\author{
Charles C. BROWN \\ University of Michigan, Ann Arbor, MI 48109, USA \\ Wallace E. OATES* \\ Department of Economics, University of Maryland, College Park, MD 20742, USA \\ Received June 1985, revised version received October 1986
}

\begin{abstract}
This paper explores the roles of different levels of government in assisting the poor. Using a model incorporating utility interdependence, the paper first presents some theoretical results indicating how levels of poor relief vary with the extent of mobility of the poor under both centralized and decentralized systems of support. It then provides a survey of the empirical work on migration of the poor along with a brief historical discussion of the experience under the English Poor Laws. The concluding section turns to normative issues and contends that mobility of the poor is a basic source of inefficiency in wholly decentralized systems of support; this inefficiency, along with certain other equity considerations, establishes a role for the central government in assistance to the poor.
\end{abstract}

Measures adopted to produce greater equality are, however, exceedingly unsuitable for local authorities. The smaller the locality the more capricious and ineffectual are likely to be any efforts it may make to carry out such a policy. It seems clearly desirable that all such measures should be applied to the largest possible area, and that subordinate authorities should be left to act, like the individual, from motives of selfinterest.

Edwin Cannan (1896)

Redistribution is intrinsically a national policy.

George Stigler (1957)

Financial assistance to the poor is a legitimate responsibility of states and localities.

President Reagan (1982)

\footnotetext{
*We are grateful to Anne Stevens and to the Computer Science Center at the University of Maryland for their valuable assistance and to the National Bureau of Economic Research and the Sloan Foundation for their support of this research. We also appreciate helpful comments on an earlier draft of this paper from Steven Craig, Edward Gramlich, Russell Mathews, David Wildasin, the participants in the Sloan Workshop in Urban Public Economics at the University of Maryland, and two anonymous referees. Finally, Oates wishes to thank Resources for the Future, where he spent a sabbatical leave as a visiting fellow while completing work on this paper.
} 


\section{Introduction}

As the epigraphs to this paper suggest, there exists a divergence of views on the appropriate intergovernmental structure of programs to assist the poor. One strand of the literature argues that the central government should assume primary responsibility for this task [e.g. Oates (1972), Ladd and Doolittle (1982)]. This contention is typically developed along two lines:

(1) The well-being of the poor is of national concern: it is a national public good in the sense that income levels of the poor enter as arguments in the utility functions of the nonpoor. As a result, individual behavior or 'local' programs will involve an externality with the consequence of suboptimal levels of support.

(2) Even if preferences were such that concern for the poor were limited to residents of one's own jurisdiction, the potential mobility of the poor toward areas with comparatively high levels of assistance would force individual localities to be excessively parsimonious in their relief programs. The point here is that:

The mobility of individual economic units among different localities places fairly narrow limits on the capacity for local income redistribution. For example, an aggressive policy to redistribute income from the rich to the poor in a particular locality may, in the end, simply chase the relatively wealthy to other jurisdictions and attract those with low incomes. The likely outcome is a community homogeneous in poor residents (an unappealing prospect for most local jurisdictions) [Oates (1977, p. 5)].

Not all of the economic literature, however, subscribes to this position [e.g. Pauly (1973), Trcsch (1981, ch. 30)]. And, in fact, actual programs for assistance to the poor have often relied heavily on decentralized finance and administration. Over several centuries under the Poor Laws, England operated a system of poor relief with basic control at the level of the local parish. More recently, existing programs in the United States exhibit a wide range of roles for the different levels of government with the Federal Government providing certain programs, the states and localities others, and with shared responsibility for some of the major assistance programs (like AFDC). The institutional structure across these programs is strikingly diverse. This is of further interest in view of President Reagan's proposal under the New Federalism to shift the major responsibility for assistance to the poor away from the central government to the state and local levels.

Our purpose in this paper is to explore the issue of poor relief in a federal system with particular attention to the implications of mobility of the poor for the design of these programs. We begin with a positive analysis. Making use of a variant of a simple and useful model of Orr (1976) with demon- 
strated explanatory power, we work through a series of conceptual exercises that describe relative levels of cash transfers to the poor under various conditions. In these exercises, we find that the mobility of poor households across jurisdictions is a critical element in determining the outcome. In particular, we demonstrate that in a partial-equilibrium framework, the level of assistance varies inversely with the 'elasticity of mobility' of low-income individuals. The extension of the analysis to a general-equilibrium setting produces some important qualifications to this finding. But using some numerical simulations, we establish the presumption that with mobile poor the movement from a centralized to a decentralized system of poor relief is likely to result in a reduced average level of assistance to the poor. Since the extent of mobility is basically an empirical matter, we next survey recent research on migration behavior in response to differentials in levels of support for the poor and on the response of benefit levels to the potential for such migration. Then, following a brief examination of the experience under the English Poor Laws, we turn in the final section of the paper to the normative implications of the analysis. Here we contend that the potential migration of poor households seriously undermines the case for a decentralized system of poor relief. Economic efficiency in such transfer programs itself requires a basic role for the central government to correct the distortions inherent in a wholly decentralized program of assistance to the poor. In addition, there are other equity and efficiency arguments that, depending on a society's values, may imply a further rationale for central intervention.

\section{A positive theory of poor relief: Partial equilibrium analysis}

Our variant of Orr's model is based on the following simplifying assumptions:

(1) The nation consists of two kinds of people: the nonpoor $(N)$ and the poor $(P)$. Within each group, all individuals are identical: they have the same preferences and the same pre-tax and pre-transfer incomes.

(2) The concern for the poor is expressed as a dependence of the utility of the nonpoor on post-transfer income levels of the poor: $U_{\mathrm{N}}^{i}=U_{\mathrm{N}}^{i}\left(\bar{Y}_{\mathrm{N}}^{i}, \bar{Y}_{\mathrm{P}}^{i}\right){ }^{1}$ Here, the utility of a nonpoor individual in local jurisdiction $i$ depends on his own post-tax income, $\bar{Y}_{\mathrm{N}}^{i}$ and on the post-transfer income of the poor, $\bar{Y}_{\mathrm{P}}^{i}$

\footnotetext{
'Following Orr, we adopt here the 'altruistic' rationale for support for the poor. There are alternatives. Varian (1980), for example, suggests income security as a motivation for poor relief: one might support assistance to the poor as an insurance policy in case one's own income falls to low levels at some future time. Yet another approach is Peltzman's (1980) vote-maximizing politician who tries to secure the votes of transfer recipients through redistributive measures.
} 
(where $\bar{Y}$ refers to disposable income). The poor care only about their own disposable income: $U_{\mathrm{P}}^{i}=U_{\mathrm{P}}^{i}\left(\bar{Y}_{\mathrm{P}}^{i}\right)$. We shall assume (as indicated by the superscript $i$ ) that the nonpoor care only about the poor within their own jurisdiction and not elsewhere. ${ }^{2}$

(3) All the poor within a particular jurisdiction receive the same amount of transfer income.

(4) Transfers within each jurisdiction are financed by equal (lump-sum) taxes per capita on the nonpoor.

(5) The median voter determines the level of taxes and transfers. The one restriction here is that $N^{i}>P^{i}$ : the number of nonpoor $\left(N^{i}\right)$ exceeds the number of poor individuals $\left(P^{i}\right)$. Otherwise, the poor could pass a measure to transfer all the income of the nonpoor to themselves.

Before exploring the implications of mobility of the poor, it is helpful as a benchmark to consider briefly the pattern of assistance to the poor in the absence of any such movement. Suppose that the distribution of individuals both poor and nonpoor - across jurisdictions is given and fixed by, say, historical circumstance. In the context of our model, we can determine the equilibrium pattern of support in any jurisdiction by simply maximizing the utility of one of the (identical) nonpoor individuals:

$$
\max U_{\mathrm{N}}^{i}=U_{\mathrm{N}}^{i}\left(\bar{Y}_{\mathrm{N}}^{i}, \bar{Y}_{\mathrm{P}}^{i}\right)
$$

subject to the condition that total receipts by the poor equal aggregate tax payments by the nonpoor (which can be stated in the form):

$$
\bar{Y}_{\mathrm{P}}^{i}=Y_{\mathrm{P}}^{i}+\frac{N^{i}}{P^{i}}\left(Y_{\mathrm{N}}^{i}-\bar{Y}_{\mathrm{N}}^{i}\right)
$$

Eq. (2) indicates that the post-transfer income of a poor individual in $i$ equals his pre-transfer income, $Y_{\mathrm{p}}^{i}$, plus the total tax payments of the nonpoor $N^{i}\left(Y_{\mathrm{N}}^{i}-\bar{Y}_{\mathrm{N}}^{i}\right)$ divided by the number of poor. It is important to note that $\left(P^{i} / N^{i}\right)$ is effectively the 'price' to a nonpoor individual of raising income per capita of the poor by $\$ 1$.

The solution to this maximization problem requires that

$$
\frac{\partial U_{\mathrm{N}}^{i}}{\partial \bar{Y}_{\mathrm{N}}^{i}}=\frac{1}{\left(P^{i} / N^{i}\right)} \frac{\partial U_{\mathrm{N}}^{i}}{\partial \bar{Y}_{\mathrm{P}}^{i}} .
$$

Eq. (3) implies that the nonpoor in $i$ will continue to transfer income to the

\footnotetext{
${ }^{2}$ Note that this assumption explicitly eliminates one of the major arguments for a central role in assistance to the poor: the contention that such assistance involves a national public good. We shall return to this matter later.
} 
poor in $i$ until the marginal utility to the nonpoor of a marginal dollar of disposable income to themselves equals the marginal utility to the nonpoor of another dollar transferred to the poor. Note that this latter quantity depends not only on the income of the poor but on the 'effectiveness' of a dollar from a nonpoor person in raising the per capita income of the poor. And this in turn depends on the relative number of poor and nonpoor in the jurisdiction. If, for example, the poor are few in number relative to the nonpoor, then it will be comparatively inexpensive to the nonpoor to raise the per capita income of the poor.

Since we have assumed that the nonpoor have identical pre-tax incomes and tastes across all jurisdictions and, likewise, that the poor have the same pre-transfer incomes irrespective of location, it follows that the pattern of assistance to the poor will depend solely on the price $\left(P^{i} / N^{i}\right)$ of raising the income level of the poor. Those poor fortunate enough to be in jurisdictions where they constitute a relatively small fraction of the population will receive relatively large transfers as compared to their counterparts in localities where the poor are a larger proportion of the residents.

More generally, however, individuals are not 'chained' to their current places of residence. In particular, the poor may have the opportunity to move away from jurisdictions providing relatively low levels of assistance to others with more generous levels of support. ${ }^{3}$ In order to say more about the properties of an equilibrium in the presence of such mobility, we must be more specific about the response of the nonpoor to the prospect of a mobile poor population. Any decisions on levels of assistance to the poor must now take into consideration not only the existing number of poor residents in the jurisdiction, but also the impact of the support level on migration behavior. One thing we can say unequivocally in this instance: an increase in the number of poor in any jurisdiction [implying a rise in $\left.\left(P^{i} / N^{i}\right)\right]$ is undesirable from the perspective of the nonpoor residents - it reduces their level of utility. This follows because, in the model, the effect of an increase in $\left(P^{i} / N^{i}\right)$ is to raise the 'price' to the nonpoor of any given level of assistance per poor person. An increase in the fraction of the population that is poor effectively increases the price of the second argument in the utility function of the nonpoor.

This would suggest that, in general, levels of assistance to the poor will be less in the prescnce of mobility than if the poor remained in their 'home' jurisdictions. For in the determination of the level of support, the nonpoor

\footnotetext{
${ }^{3} \mathrm{We}$ shall continue to assume that the nonpoor do not move in response to differentials in assistance programs. This seems reasonable for, as Gramlich and Laren (1984) observe, ‘.. at today's levels, a 30 percent increase in average AFDC benefit levels would raise the disposable income of AFDC recipients approximately this amount, but reduce the disposable income of average income taxpayers by only one-third of one percent' (pp. 495-496). It would thus seem that existing differentials in taxation of the nonpoor to finance transfers to the poor are probably too small to exert much effect in themselves on the location decisions of the nonpoor.
} 
must now subtract from the utility they derive from a higher level of assistance to the poor not only the cost to themselves of the transfers to existing poor residents, but also the cost of the payments to the newly arrived poor who will migrate in response to the higher support levels [Boadway and Wildasin (1984, pp. 509-511)].

We shall now provide a formal proof of this proposition in our partialequilibrium framework. We introduce an explicit 'migration function' in which the number of poor in a jurisdiction is a function of the level of transfer payments:

$$
P=f(T), \quad \text { where } f^{\prime \prime}(T)>0 \text { and } f^{\prime} \cdot \frac{T}{P}=\eta
$$

The parameter $\eta$ is the elasticity of the migration function. ${ }^{4}$ Substituting the budget constraint into the utility function, we can write:

$$
U_{\mathrm{N}}\left[\bar{Y}_{\mathrm{N}}, \bar{Y}_{\mathrm{P}}\right]=U_{\mathrm{N}}\left[Y_{\mathrm{N}}-\frac{P T}{N}, Y_{\mathrm{P}}+T\right]
$$

Differentiating (5) with respect to $T$ and setting the resulting expression equal to zero yields:

$$
\begin{aligned}
Z(T, \eta) & =\frac{\partial U_{\mathrm{N}}}{\partial \bar{Y}_{\mathrm{N}}}\left\{-\frac{P}{N}-\left(\frac{T}{N} \cdot \frac{\mathrm{d} P}{\mathrm{~d} T}\right)\right\}+\frac{\partial U_{\mathrm{N}}}{\partial \bar{Y}_{\mathrm{P}}} \\
& =\frac{\partial U_{\mathrm{N}}}{\partial \bar{Y}_{\mathrm{N}}}\left\{-\frac{P}{N}(1+\eta)\right\}+\frac{\partial U_{\mathrm{N}}}{\partial \bar{Y}_{\mathrm{P}}}=0 .
\end{aligned}
$$

By the implicit-function rule, we obtain:

$$
\frac{\mathrm{d} T}{\mathrm{~d} \eta}=-\frac{\partial Z / \partial \eta}{\partial Z / \partial T}
$$

where $\partial Z / \partial T=\partial^{2} U_{\mathrm{N}} / \partial T^{2}<0$ by the second-order condition for utility maximization. Next, we note that

$$
\frac{\partial Z}{\partial \eta}=\frac{\partial U_{\mathrm{N}}}{\partial \bar{Y}_{\mathrm{N}}}\left(-\frac{P}{N}\right)<0 .
$$

\footnotetext{
${ }^{4}$ We note, in this regard, that it is the total number of poor (not the number of migrants) that appears in the denominator of the elasticity formula. In addition, to simplify notation in this section, we have omitted the subscripts and superscripts identifying the particular jurisdiction. All variables are understood to refer to the same, say the $i$ th, jurisdiction.
} 
From (7) and (8) it follows that

$$
\frac{\mathrm{d} T}{\mathrm{~d} \eta}<0
$$

Eq. (9) indicates that the level of transfer payments varies inversely with the elasticity of the migration function; in a loose sense, it tells us (as expected) that the greater the potential flow of migrant poor in response to a change in the lcvel of transfers, the lower will be the jurisdiction's level of support for the poor. This result, however, must be interpreted quite carefully. Note that the sign of this derivative is determined while holding $T$ and $P$ constant; we are effectively rotating the migration function around some initial values for $P$ and $T$.

This can be seen in fig. 1, which depicts the 'demand curve' for transfer payments $(D)$ by the nonpoor and a migration curve $(M)$. The $M$-curve indicates that the number of poor residents (and hence $P / N$ ) rises with the level of support payments. ${ }^{5}$ Note that an equilibrium pattern of payment levels and poor residents can only occur at the intersection of the $D$ and $M$ curves - at point $A$ corresponding to the solid curves. If, for example, $T>T_{0}$,

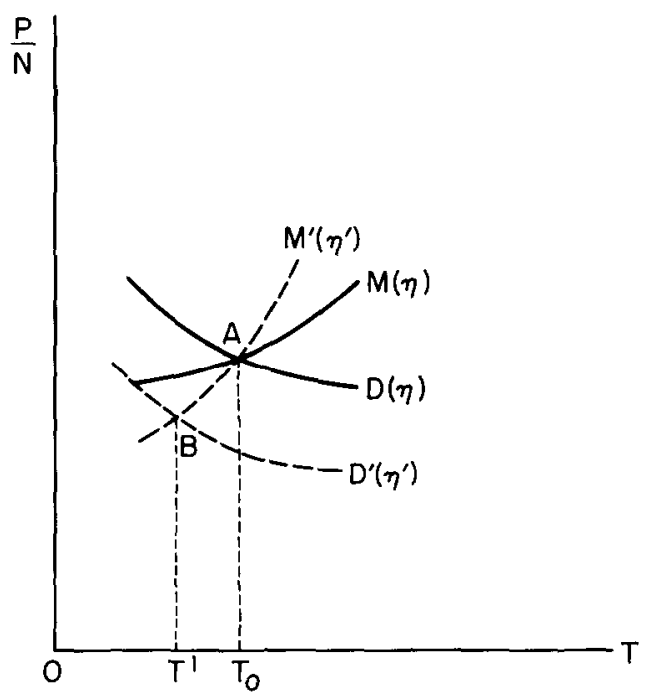

Fig. 1

\footnotetext{
${ }^{5}$ The $M$-curve in lig. 1 represents the locus of points satisfying the mobility function described by eq. (4). The $D$-curve corresponds to eq. (6): it is the locus of points satisfying the conditions for utility-maximization of the nonpoor. As is evident from eq. (6), the $D$-curve depends on the 'elasticity of migration' $(\eta)$.
} 
then more poor would enter the jurisdiction pushing down the level of transfer payments until $T=T_{0}$. In terms of fig. 1, our result in eq. (9) says that if we rotate the $M$ curve about the initial position at point $A$ and increase the elasticity of the function by making the curve steeper (see $M^{\prime}$ ), then the equilibrium level of $T$ will fall. This occurs because the demand function itself depends upon the slope of the migration curve: as $M$ becomes steeper, indicating a greater responsiveness of the poor to payment levels, the $D$-curve shifts down (to $D^{\prime}$ in the diagram) reflecting a lower desired level of transfers. The new equilibrium is at $B$, indicating a fall in support payments from $T_{0}$ to $T^{1}$. It is important to be quite precise concerning this interpretation of (9). For, as we shall see in the next section, shifts of the $M$-curve in one direction may not yield a predictable effect on the level of support payments.

\section{A two-jurisdiction, general-equilibrium model}

A partial-equilibrium analysis is not, however, wholly satisfactory, since there will typically exist some interrelationship among levels of support among jurisdictions. In this section we examine the properties of a simple, two-jurisdiction model where we introduce simultancous utility-maximization across the two localities. This provides some further insights into the way in which the degree of mobility of the poor influences the equilibrium levels of transfer payments.

Heretofore, we 'defined' mobility in terms of a mobility function. We effectively identified an increase in mobility with an increase in the parameter $\eta$, the elasticity of the mobility function. Higher mobility was thus associated with more responsiveness in the location decisions of the poor with respect to the level of support payments. For our two-jurisdiction case, we shall usc a related, but somewhat different, measure of mobility: the 'cost' of moving from one jurisdiction to the other. We understand such moving costs to include the net costs of all considerations besides transfers. This would include not only transport costs (e.g. the price of 'bus tickets'), but also the psychic costs of relocation. In addition, moving costs depend upon such conditions as the length of the residency period before a low-income individual becomes eligible for support payments. From this latter perspective, the Supreme Court decision striking down state residency requirements can be seen as reducing the cost of relocation.

For the $k$ th poor individual in jurisdiction $i$, the decision as to whether to move to jurisdiction $j$ will depend upon the difference in support payments relative to moving costs. More formally, individual $k$ will emigrate from $i$ to $j$ if

$$
T^{j}-T^{i}>C_{k}^{i}+\alpha
$$


where $\alpha$ represents a component of moving costs common to all individuals and $C_{k}^{i}$ an individual-specific 'attachment'. ${ }^{6}$ A change $\mathrm{d} \alpha$ increases moving costs by $\mathrm{d} \alpha$ for each individual. It is changes in this parameter $\alpha$ that we will use to generate different equilibria at varying levels of moving costs (or, inversely, at different levels of mobility). If we let $F^{i}(C)$ and $P_{0}^{i}$ represent the cumulative distribution function of $C$ and the initial number of poor in jurisdiction $i$, then

$$
P^{i}\left(T^{j}-T^{i}, \alpha\right)=P_{0}^{i}-P_{0}^{i} F^{i}\left(T^{j}-T^{i}-\alpha\right)+P_{0}^{j} F^{j}\left(T^{i}-T^{j}-\alpha\right) .
$$

The first term on the RHS of (11) is the initial stock of poor, the second the number of poor who emigrate from $i$, and the third the number who come to $i$ from the other jurisdiction. Although (11) takes the form of a stockadjustment process, we note that the model is not itself dynamic in character; we shall make use of (11) in describing the comparative-statics outcomes associated with changes in the parameter $\alpha$.

If each jurisdiction takes the other's behavior as given, it will choose $T^{i}$ (or $T^{j}$ ) to maximize

$$
U_{\mathrm{N}}^{i}\left(\bar{Y}_{\mathrm{N}}^{i}, \bar{Y}_{\mathrm{P}}^{i}\right)=U_{\mathrm{N}}^{i}\left[Y_{\mathrm{N}}-\frac{T^{i} P^{i}\left(T^{j}-T^{i}, \alpha\right)}{N^{i}}, Y_{\mathrm{P}}^{i}+T^{i}\right]
$$

Differentiating with respect to $T^{i}$ and setting the result equal to zero gives:

$$
Z \equiv \frac{\partial U_{\mathrm{N}}^{i}}{\partial \bar{Y}_{\mathrm{N}}^{i}} \cdot \frac{\partial \bar{Y}_{\mathrm{N}}^{i}}{\partial T^{i}}+\frac{\partial U_{\mathrm{N}}^{i}}{\partial \bar{Y}_{\mathrm{P}}^{i}}=0, \quad \text { for } i=1,2
$$

Changes in $\alpha$ will then lead to changes in $T^{i}$ and $T^{j}$. These can be either partial- or general-equilibrium responses. For a partial-equilibrium analysis, we can differentiate (13) for jurisdiction $i$ with respect to $T^{i}$ and $\alpha$, and solve

$$
\frac{\partial Z^{i}}{\partial T^{i}} \mathrm{~d} T^{i}+\frac{\partial Z^{i}}{\partial \alpha} \mathrm{d} \alpha=0, \quad \text { for } \frac{\mathrm{d} T^{i}}{\mathrm{~d} \alpha} .
$$

\footnotetext{
${ }^{6} C_{k}^{i}$ is related to what Grewal and Mathews (1983) have termed the 'locational surplus'. This surplus is the 'algebraical sum of the net benefits which a citizen perceives as accruing to him, in terms of his consumption and production/employment activities as well as his fiscal transactions with governments, by choosing to remain in his present jurisdiction rather than migrating to another jurisdiction' (p. 9). In our notation, $\left(C_{k}^{i}+T^{i}-T^{j}\right)$ is the locational surplus for the $k$ th low-income household in jurisdiction $i$. We should also note, as a referee pointed out, that moving and attachment costs in eq. (10) must be understood to be annualized costs to make them commensurate with transfer payments. Alternatively, we could take the left-hand side of (10) to represent the present discounted value of the difference between the future streams of transfer payments.
} 
For a general-equilibrium analysis, we differentiate each equation in (13) with respect to $T^{i}, T^{j}$, and $\alpha$ and solve the system of equations,

$$
\left[\begin{array}{ll}
\partial Z^{1} / \partial T^{1} & \partial Z^{1} / \partial T^{2} \\
\partial Z^{2} / \partial T^{1} & \partial Z^{2} / \partial T^{2}
\end{array}\right]\left[\begin{array}{l}
\mathrm{d} T^{1} \\
\mathrm{~d} T^{2}
\end{array}\right]=-\left[\begin{array}{l}
\partial Z^{1} / \partial \alpha \\
\partial Z^{2} / \partial \alpha
\end{array}\right] \mathrm{d} \alpha
$$

for $\mathrm{d} T^{1} / \mathrm{d} \alpha$ and $\mathrm{d} T^{2} / \mathrm{d} \alpha$. To label the resulting algebra 'tedious' is an understatement. Here, we merely outline the solution; details appear in an appendix available from the authors on request.

Differentiating eq. (13) leaves us with three sorts of derivatives: firstpartials of the utility function, second- and cross-partials of the utility function, and derivatives of $P^{i}$ with respect to its arguments. The first-partials are, of course, positive. Various combinations of the other derivatives of the utility function can be signed either from the second-order conditions for each jurisdiction's maximization of (12) or from strongly-held priors about related comparative-static experiments. In particular, we assume that

$$
\frac{\partial T^{i}}{\partial Y_{\mathrm{N}}^{i}}>0 \text { and } \quad \frac{\partial T^{i}}{\partial \bar{Y}_{\mathrm{P}}^{i}}<0
$$

The third source of information comes from actually differentiating $P^{i}$ with respect to its arguments. Most of our conclusions take advantage of the fact that the sum of $P^{1}$ and $P^{2}$ is constant, and that the assumed response of migration from $i$ to $j$ is based on the linear function $\left(T^{j}-T^{i}-\alpha\right)$. Finally, we assume that $F^{i \prime \prime}$ is non-negative or, equivalently, that the density of $C$ is rising. ${ }^{7}$

In both the partial- and general-equilibrium contexts, our results are qualitatively similar. An increase in $\alpha$ will reduce both of the migration flows in eq. (11), reducing the number of poor in one jurisdiction and increasing it in the other. For the jurisdiction which is on the receiving end of the net migration flow, we can say unambiguously that an increase in the mobility of the poor (i.e. a reduction in $\alpha$ ) will result in a decline in the level of transfer payments. Increased mobility implies an increased inflow of low-income individuals for any specified level of transfer payments. The response of the nonpoor to this increase in the potential inflow of transfer recipients will be to lower support levels. For the other jurisdiction, however, the effect is ambiguous. Increased mobility implies a greater net outflow of the poor; with

\footnotetext{
${ }^{7}$ For any symmetric density, this holds when less than half the poor are migrating. Allowing $F^{i \prime \prime}$ to be negative introduces an ambiguity into our results rather than necessarily reversing them; it turns out that increases in $\alpha$ necessarily correspond to reductions in the elasticity of $P$ with respect to $T$ only when $F^{\prime \prime}$ is positive.
} 
fewer poor, the 'price' $(P / N)$ of raising the disposable income of the poor falls. This effect encourages an increase in the level of transfers and works against the incentive to reduce payments in response to the higher level of mobility. We cannot, in general, determine the sign of $d T / d \alpha$ for such a jurisdiction.

More particularly, if we were to limit migration flows to a one-way movement of the poor from the low-transfer to the high-transfer state, we could show that with increased mobility, the level of transfers would unambiguously decline un the high-support state but could conceivably either rise or fall in the low-transfer state (because of the exodus of some of its poor). Gramlich (1985), using a specific formulation of a model in this spirit with representative values for the parameters, produces some intriguing results. In his simulation exercises, increased mobility of the poor results in a dramatically reduced level of transfers $(T)$ in the high-support state and an increase in $T$ in the low-support state. Greater mobility of the poor effectively pushes support levels closer together with a sharp decrease in the average payment across the two jurisdictions. The decrease in the average payment is an interesting, if perhaps an unsurprising, finding. We shall present some evidence shortly that reinforces this finding. While it is our conjecture that a decrease in the average payment is probably the 'typical' outcome under increased mobility of the poor, we would note that it is not a proposition that we have been able to derive as a general result.

\section{Centralized versus decentralized support for the poor}

Having examined the effects of mobility of the poor on levels of support under a system of local poor relief, we turn next to a comparison of support levels under centralized and decentralized systems of assistance.

It is helpful at the outset to examine some of the properties of the centralized outcome using the two-jurisdiction model. Consider the following numerical example:

$$
\begin{array}{ll}
N_{1}=200, & P_{1}=60, \\
N_{2}=100, & P_{2}=40,
\end{array}
$$

where $N_{i}$ and $P_{i}$ refer to the number of nonpoor and poor households, respectively, in jurisdiction $i$ (where $i=1,2$ ). We retain the assumption that the nonpoor care only about the well-being of the poor within their own jurisdiction. Centralization of support has two effects. First, it equalizes the price of support for the poor across the two jurisdictions. Under centralized 
support, it is as if both jurisdictions had ratios of poor to nonpoor of

$$
\frac{P}{N}=\frac{P_{1}+P_{2}}{N_{1}+N_{2}}=\frac{60+40}{200+100}=\frac{1}{3}
$$

Note that the distribution of the poor across jurisdictions is irrelevant to the centralized outcome (even though it remains true that the nonpoor are only concerned with the poor within their own locality). Since in our simple model the nonpoor are everywhere identical, they will all desire the same level of transfer payments - that corresponding to the price $P / N$. Second, by equalizing levels of transfer payments, centralization eliminates any movement of poor households in response to interjurisdictional differentials in support levels. The mobility issue thus vanishes.

Suppose that we take such a centralized outcome as our initial equilibrium and consider a shift to a decentralized system of poor relief. In terms of our numerical example, jurisdiction 1 will now provide for its own poor as will jurisdiction 2. Decentralization will involve two effects: a price effect and a mobility effect. The sign of the mobility effect is unambiguous: as noted earlier, each jurisdiction will incorporate into its choice of a level of transfer payments the prospect that a higher ' $T$ will, ceteris paribus, result in a larger number of poor households. This will depress the level of transfers. The price effect, however, will differ between the two jurisdictions. In our example, jurisdiction 1 (with a comparatively small fraction of poor residents) will experience a fall in the 'price' of transfer payments to its poor. This will tend to offset the mobility effect so that the impact of decentralization on $T_{1}$ is uncertain. For jurisdiction 2, in contrast, the price of transfers rises; this reinforces the mobility effect and leads to an unambiguous fall in $T_{2}$. Because of the ambiguous sign for jurisdiction 1, we cannot demonstrate that decentralization will necessarily lower the average level of transfers, although we might expect this often to be the case. That is, we might expect that in most circumstances, the average level of transfer payments under a decentralized system of assistance to the poor would be less than the average payment level under a centralized outcome. But cven this fairly wcak result rests on our assumption of identical tastes of nonpoor individuals in the two jurisdictions.

To obtain some further sense of these relationships, we have undertaken some numerical exercises using specific functional forms for our twojurisdiction case. For these exercises, we have normalized the pre-transfer income to the nonpoor at 1.0 and set the pre-transfer income of the poor at 0.25 . We assumed a utility function of the simplified-CES form:

$$
U=\left[\bar{Y}_{\mathrm{N}}^{(-r)}+b \bar{Y}_{\mathrm{P}}^{(-r)}\right]^{-(1 / r)}
$$


where $\sigma=1 /(1+r)$ is the elasticity of substitution between $\bar{Y}^{\mathbf{N}}$ and $\bar{Y}^{\mathrm{P}}$. We arbitrarily chose five values of $\sigma: 0.33,0.67,1.0,2.0$, and 3.0. For each $\sigma$, we picked $b$ so that $\bar{Y}_{\mathrm{P}} / \bar{Y}_{\mathrm{N}}$ equalled 0.40 when transfers were provided under a fully centralized system. ${ }^{8}$

We assumed the moving-cost functions $F^{i}\left(T^{j}-T^{i}-\alpha\right)$ to be cumulativenormal distributions, with variance one and means of 1.2817 and 1.0365, respectively. Thus, in a benchmark world where moving costs are zero and transfers in the two jurisdictions are equal, $F^{1}=\phi(-1.2817)=0.10$ and $F^{2}=$ $\phi(-1.0365)=0.15$ [where $\phi(z)$ is the standard-normal c.d.f.]. This implies that, in our benchmark case, the number of poor in each jurisdiction is constant, since $F^{1} P_{1}=0.10 \times 60=6$ move from 1 to 2 and $F^{2} P_{2}=0.15 \times 40=6$ move from 2 to 1 .

The results appear in table 1 . The level of transfers under a centralized system is independent of $\sigma$ by construction; $b$ was chosen for each $\sigma$ to generate this property. The first major result is that when $\alpha=\infty$ (no mobility), decentralization can either raise or lower average transfers. When $\sigma<1$, the demand curve in fig. 1 is concave, so that $T$ at $P / N=0.33$ (the centralized solution) exceeds the weighted average of $T$ at $P / N=0.3$ and $T$

Table 1

Transfers under centralized and decentralized systems.

\begin{tabular}{llllll}
\hline & \multicolumn{2}{l}{ Elasticity of substitution } & & \\
\cline { 2 - 5 } & 0.33 & 0.67 & 1.0 & 2.0 & 3.0 \\
\hline Centralized system & 0.13235 & 0.13235 & 0.13235 & 0.13235 & 0.13235 \\
Decentralized system: $x=x$ & & & & & \\
$T_{1}$ & 0.14613 & 0.15868 & 0.17157 & 0.21237 & 0.25648 \\
$T_{2}$ & 0.10987 & 0.09128 & 0.07353 & 0.02500 & 0.01695 \\
$\bar{T}^{2}$ & 0.13163 & 0.13172 & 0.13235 & 0.13742 & 0.14711 \\
Decentralized system: $x=0$ & & & & & \\
$T_{1}$ & 0.14085 & 0.14745 & 0.15373 & 0.17084 & 0.18564 \\
$T_{2}$ & 0.10466 & 0.08337 & 0.06475 & 0.02022 & 0.01293 \\
$\bar{T}$ & 0.12637 & 0.12182 & 0.11814 & 0.11059 & 0.10621 \\
\hline
\end{tabular}

${ }^{8}$ In a centralized system, $P / N$ equals $1 / 3$ and there are no $\partial P / \hat{\partial} T$ terms in the first-order conditions. As a result,

$$
\frac{\bar{Y}_{\mathrm{P}}}{\overline{\mathrm{Y}}_{\mathrm{N}}}=\left(\frac{b}{P / N}\right)^{a} \text {. }
$$

Since the left-hand side is fixed at 0.40 and $P / N$ is known, it is easy to solve for $b$ as a function of $\sigma$. The values of $Y_{\mathrm{P}}$ and $T$ were chosen as representative of actual 1983 data: families receiving 'public assistance and welfare' received an average transfer of $\$ 3,245$, bringing their total income to $\$ 8,329$. Average family income before taxes was $\$ 24,646$. [See U.S. Bureau of the Census (1985, tables 33 and 34).] 
at $P / N=0.4$. When $\sigma>1$, the reverse is true. Of course, these comparisons hold for 'large' finite $\alpha$ 's as well as the polar case in the table. With immobile poor, there is thus no presumption in our model that the average level of transfer payments will be higher or lower under centralized assistance than under localized support for the poor.

The second major result is that increased mobility reduces transfers in each jurisdiction (compare the $\alpha=\infty$ and $\alpha=0$ results). This happens for a range of intermediate values, too (and for other $\bar{Y}_{p}, T$ pairs), although we cannot show this result need always hold. Interestingly, our finding that transfers fall in the jurisdiction with more poor people contrasts with the implication of the Gramlich-Laren (1984) model [as developed in Gramlich (1985)]. As noted earlier, Gramlich finds that, in his simulations, benefits in the poorer jurisdiction rise. This difference appears to result from the choice of functional form, especially for the migration function. ${ }^{9}$ At any rate, it is the case in both the Gramlich and our simulations that in the presence of mobility of the poor, average support payments are lower under a system of local poor relief than under a centralized system of assistance. The extent of mobility of transfer recipients seems to be of great importance to the outcome.

\section{An examination of the evidence}

Our theoretical analysis suggests that migration of the poor in response to differentials in transfers has the potential to depress the levels of these payments. But is there evidence that this has taken place? We shall organize our discussion of the empirical literature around the following two issues:

(1) Is there evidence to indicate that the poor do, in fact, migrate from lowbenefit to high-benefit jurisdictions (and in substantial numbers)?

${ }^{9}$ Neglecting matching grants, the Gramlich-Laren model can be written

$$
\ln T^{i}=\frac{1}{1+c b}\left(a_{i}+c b \ln T^{j}\right),
$$

where $c$ is the price elasticity of demand for $T, b$ is the elasticity of $P^{i}$ with respect to $T^{i} / T^{j}$, and the $a_{i}$ are constant terms reflecting other influences [see Gramlich $(1985, \mathrm{p} .63)$ ]. The equilibrium levels of transfers are

$$
\ln T^{i}=\frac{a_{i}+c b\left(a_{1}+a_{2}\right)}{1+2 c b} .
$$

The derivative of $\ln T^{i}$ with respect to $b$ is

$$
\frac{c\left(a_{j}-a_{i}\right)}{(1+2 c b)^{2}}
$$

Thus, increased mobility (higher $b)$ reduces transfers in the higher-transfer state $\left(a_{i}>a_{j}\right)$, and increases them in the low-transfer state. Note, however, that the sum of these derivatives must be zero, which is a very strong a priori restriction. 
(2) Can we find any response in the level of transfer payments to such migration?

We begin with a brief survey of a large number of econometric studies of migration behavior in the United States that have addressed the first of these issues. These studies typically relate migration over some period between states (or, in some instances, metropolitan areas) to a set of independent variables including measures of per capita income, unemployment rates, etc., in addition to variables indicating welfare benefits in (or differentials in benefits between) the jurisdictions. Some of the early studies were quite crude and aggregative [e.g. Gallaway et al. (1967)]. Using total migration flows, they typically found the welfare-support variables to be statistically insignificant. It is also worth noting that several of these studies used migratory data from the 1950s, when payment levels and differentials were relatively small and various residency requirements were in effect. In contrast, many later studies employed more disaggregated data on migratory flows for more recent periods. These studies typically distinguish between white and nonwhite migration and, in some instances, between different age groups. And many of them use data from the decade of the $1960 \mathrm{~s}$. One would have to characterize the findings of these studies as somewhat mixed. But our survey indicates that the large majority of them find some evidence of positive net migration of nonwhite individuals in response to differentials in welfare benefits [see, for example, Kaun (1970), Cebula et al. (1973) and Curran (1977)].

Nonwhite migration, however, is itself an imperfect proxy measure for benefit-induced migration. As Gramlich and Laren (1984) note, only about one-quarter of nonwhite families are recipients of AFDC payments, and only about one-half of AFDC recipients are nonwhite. It would obviously be preferable to target such migration studies on actual (or potential) welfare recipients. Some recent studies have done just this. Southwick (1981) has explored the migratory patterns of AFDC recipients and finds that benefit levels exert a strong influence on AFDC immigration. In his 'Test 5', for example, Southwick estimates a 'migration' elasticity of 2.5: his table 5 indicates that a 10 percent increase in AFDC benefits will lead to an estimated increase of 25 percent in the in-migration of welfare recipients. ${ }^{10}$ Likewise, Blank (1983), drawing on micro data for individual AFDC recipients from the Current Population Survey, finds that benefit levels (as well as employment opportunities) exert a significant influence on location decisions. Finally, Gramlich and Laren (1984) have used two quite different

\footnotetext{
${ }^{10}$ Southwick's elasticity of migration, incidentally, is not the same as the elasticity of our migration function in the preceding section. For Southwick's calculations, the elasticity of migration is defined as the percentage change in the number of migrant poor (not total poor) resulting from a 1 percent change in the level of transfer payments (in this case the monthly AFDC benefit).
} 
techniques to estimate the migratory response to benefit levels. The first involves the estimation of a simultaneous-equation model using pooled timeseries and cross-sectional data on state AFDC payments for 1974-81; the second employs micro data from a subsample of the 1980 Census and the Panel Study of Income Dynamics (PSID) to estimate a 'transition matrix' describing movements among groups of states with differing benefit levels. Both of these exercises reveal a significant migratory movement of AFDC beneficiaries from lower to higher benefit states. This movement, incidentally, is not large in the short run. Gramlich and Laren describe it as 'sluggish', but over a longer period this mobility "can alter the interstate distribution of the AFDC population substantially' (p. 506).

The evidence thus provides some support for the view that benefit differentials exert a significant influence on the location decisions of the poor. But is this migratory response to differentials in support levels perceived by state and local policy-makers, and do they react by holding benefits below what they otherwise would be? As we noted earlier, this is a difficult issue to get at empirically. Interestingly, there has been a recognition in the empirical literature that actual migration flows may influence benefit levels. Cloward and Piven (1968), for example, have argued that the movement of blacks from the South to northern cities led to an increase in the political power of blacks in the cities with a consequent expansion of welfare rolls and benefit levels. The claim here is that actual migration is associated with increases (not decreases) in welfare benefits, in response to the expanded, and hence politically more influential, group of transfer recipients. The first empirical test of this hypothesis is embodied in the estimation of a two-equation model by Cebula (1974); the model contains one equation explaining migration flows and a second describing the response of benefit levels to these flows. In the second equation, Cebula found a direct and significant relationship between the level of benefits and the inflow of nonwhite migrants. However, later work casts doubt on these initial findings. Criticizing Cebula's work, Kumar (1977) has estimated a somewhat different model using Cebula's (and other) data; he finds no significant impact of migration flows on the level of assistance payments. Likewise, Curran (1977), in the estimation of a threeequation model of net immigration of nonwhites to SMSAs between 1965 and 1970 , can find no evidence that greater immigration of nonwhites leads to higher welfare payments. And, finally, Southwick (1981), estimating a twoequation model, finds that migration flows of welfare recipients do not have a significant effect on benefit levels. The evidence, on the whole, does not seem to support this version of the 'bi-directional' hypothesis.

However, the hypothesis of interest to us is that potential migration depresses benefit levels; the proposition is that public officials, responding to the potential movements of low-income households, select benefit levels below those they would choose in the absence of such mobility. The one 
attempt to conceptualize and measure this relationship is the simultaneousequation model, noted earlier, by Gramlich and Laren. Their model incorporates explicitly the differential between own-state and surrounding-state benefit levels and its effect on the size of the welfare population. This, in turn, enters into the determination of the level of welfare benefits (which results from utility-maximization of the decisive voter). Their estimated benefit equation indicates that the "migration effect [on benefit levels] is strong and significant no matter how the model is estimated' (p. 499). In short, the greater the potential migration of benefit recipients, the lower are the support-payment levels predicted by the Gramlich and Laren equation.

Our reading of the evidence, at this juncture, is that it provides some support both for the view that there is a migratory response to differentials in benefit levels and that the recognition of this migration potential depresses levels of assistance payments. As Gramlich and Laren (1984) put it:

Our tentative conclusion is that migration of AFDC beneficiaries does appear to be an important phenomenon, though only in the very long run. It does appear to be perceived that way by state legislators, who appear to be very much conditioned by what other states are doing when they set AFDC benefits (p. 510).

\section{Local assistance to the poor: The case of the English Poor Laws}

Our analysis and some supporting evidence suggest that mobility of the poor in response to differentials in support is a potentially serious obstacle to the successful functioning of a system of local finance. This raises the intriguing question of how England, a relatively small country with short distances between local parishes, managed to operate a system of local relief over several centuries. Although the Elizabethan or Old Poor Law was officially enacted in 1601, it effectively codified practices that had existed for some time [Marshall (1968, p. 11)]. Under these practices, the basic responsibility for both the finance and administration of poor relief rested with the parish. The Old Poor Law required each parish to designate an 'Overseer of the Poor' whose task it was to know all the poor, to administer assistance to them, and to find work for the unemployed.

The English dealt with the problem of migration by prohibiting it. The Law of Settlement and Removal of 1662 (which again formalized earlier practices reaching back at least to the Labour Ordinance of 1349) made it the responsibility of each parish to provide relief for its own, but only its own, poor. Under the Law, church wardens and overseers were directed to remove to his 'home' parish any newcomer likely to become a burden to his adopted parish unless the new arrival could give surety that he would not become indigent or rented property of the value of ten pounds per year or 
more [Fraser (1976, pp. 26-27)]. In fact, the history of the Poor Laws is largely an account of efforts to deny support to, and to deport, the itinerant poor. Cruel instances abound of whippings, the splitting of families, and the expulsion of widows and unwed mothers. In a further Act in 1795, the settlement law was amended such that only those who applied for local relief were subject to removal. Now only the poor who actually applied for support put themselves in jeopardy of being removed. The threat of removal proved a powerful force in persuading strange paupers to conceal their neediness. The settlement and removal provisions were a cornerstone of the Poor Laws. Even with the enactment of the New Poor Law in 1834 with its attempt to centralize and standardize somewhat the treatment of the poor, settlement and removal was left intact; it survived well into the twentieth century.

In addition to the hardship that it worked on the poor, the settlement law proved quite complex and costly to administer. The removal of a poor person could involve a long and expensive search to determine the person's most recently acquired 'settlement', sometimes involving extensive litigation with other parishes. Such litigation could drag on encompassing one parish after another, until the bill became quite sizeable.

It took seven years for a case brought by the township of Carlton in Yorkshire against Marsden in Lancashire to be settled, and when the Court of the Queen's Bench finally decided the issue in 1849, the 142 ratepayers of Carlton were left with a legal bill of over 300 pounds [Fraser (1976, pp. 34-35)].

Added to this was the cost of actual removal and transport; Tate (1969, p. 200 ) notes that constables on the main roads sometimes spent the whole of their time transporting paupers.

During the nineteenth century, an alternative to settlement and removal procedures became popular. Instead of having a relief applicant and his family returned to them under a removal order with little prospect of gainful employment, the parish of settlement sometimes elected to reimburse the parish where the relief recipient was currently located. As Fraser (1976, pp. 35-36) points out: 'A complex system of inter-parochial and inter-union accountancy sprang up... Between 1846 and 1859 the Chorlton-on-Medlock Union was reimbursing 36 unions and parishes, and was at the same time in receipt of payments from about 100 unions or parishes on behalf of their non-resident paupers.'

In view of the cumbersome and expensive character of the English system, one wonders at its longevity. The laws of settlement and removal, in particular, were the subject of fierce criticism from various social reformers and from economists of the stature of Smith and Malthus. The economists 
opposed these provisions because they restricted the mobility of labor. ${ }^{11}$ However, the support for maintaining the local system of poor relief was strong. There was deep distrust of proposals that would replace local with national financing of relief. The source of this distrust was largely the concern that effective control be maintained over recipients and levels of support [Fraser (1976, pp. 42-43)]. Local experience and direct contact with poor persons were seen as necessary to restrict assistance to the truly deserving poor. Moreover, local funding provided a check on levels of assistance that, some feared, would be lost under a system of national finance. In short, a national system of poor relief, it was argued, would lead to a 'profusion' of assistance to the poor that would encompass fraudulent recipients and discourage work effort.

Of central interest for our treatment, however, are the provisions for settlement and removal. Without such provisions to thwart the movement of the poor from one parish to another in search of more generous support, it seems doubtful that much in the way of local poor relief could have been sustained. Meager as such support may have been over much of the period under consideration, poor relief would probably have been even less without some control over the mobility of potential recipients.

\section{The normative issue}

In the preceding sections we have developed a descriptive theory of poor relief in a federal system and have explored the empirical literature that bears on the issues raised by the theory. We now turn to the normative matter posed at the outset of the paper concerning the roles of different levels of government in providing assistance to the poor. In particular, we are interested in what sorts of insights we can gain from the positive analysis into the design of an effective intergovernmental system of income maintenance.

The simple two-jurisdiction model of section 3 can be used to highlight some of the important issues which arise in a federal system. As others [e.g. Boadway and Wildasin (1984, pp. 505-511)] have noted, migration imposes a garden-variety externality that renders a completely decentralized system inefficient. Pareto efficiency (thinking only of the nonpoor in the two jurisdictions) requires that we maximize $U_{\mathrm{N}}^{1}\left(\bar{Y}_{\mathrm{N}}^{1}, Y_{\mathrm{P}}^{1}+T^{1}\right)$ subject to $U_{\mathrm{N}}^{2}\left(\bar{Y}_{\mathrm{N}}^{2}, Y_{\mathrm{P}}^{2}+T^{2}\right)$ bcing equal to some $\bar{U}_{\mathrm{N}}^{2}$. The social budget constraint is

$$
\bar{Y}_{\mathrm{N}}^{1}=Y_{\mathrm{N}}^{1}-\frac{P^{1} T^{1}+N^{2}\left(\bar{Y}_{\mathrm{N}}^{2}-Y_{\mathrm{N}}^{2}\right)+P^{2} T^{2}}{N^{1}} .
$$

\footnotetext{
${ }^{11}$ Blaug (1963) and others contend that settlement and removal were not, in practice, so serious an impediment to labor mobility as was believed by reformers of the time.
} 
The choice variables are $T^{1}, \bar{Y}_{\mathrm{N}}^{2}$, and $T^{2}$. The first-order conditions, after some manipulation, yield as a rule for efficiency:

$$
\frac{\partial U_{\mathrm{N}}^{i} / \partial \bar{Y}_{\mathrm{P}}^{i}}{\partial U_{\mathrm{N}}^{i} / \partial \bar{Y}_{\mathrm{N}}^{i}}=\frac{P^{i}+T^{i}\left(\partial P^{i} / \partial T^{i}\right)+T^{j}\left(\partial P^{j} / \partial T^{i}\right)}{N^{i}}, \quad i=1,2 .
$$

Comparing (14) to eq. (6) or (13) makes it clear that the inefficiency is not the result of jurisdiction $i$ allowing its choice of $T$ to be affected by costs to it from transfer-induced in-migration; the source of the distortion is rather that jurisdiction $i$ gets no credit for the savings an increase in its transfers would bring to the other jurisdiction.

We can imagine trying to satisfy this efficiency condition by allowing each jurisdiction to subsidize the transfers of its neighbor. Let $s^{i}$ be the subsidy per dollar of transfer which $j$ offers to $i$. To obtain an expression for $s^{i}$, we can use the fact that $\partial P^{j} / \partial T^{i}$ is equal to minus $\partial P^{i} / \partial T^{i}$, and rewrite the righthand side of eq. (14) as

$$
\frac{P^{i}\left[1+\eta^{i}-\left(T^{j} / T^{i}\right) \eta^{i}\right]}{N^{i}}
$$

where $\eta^{i}=\left(\partial P^{i} / \partial T^{i}\right)\left(T^{i} / P^{i}\right)$. The Pigouvian subsidy rate needed to internalize the externality is therefore

$$
s^{i}=\frac{T^{j}}{T^{i}} \frac{\eta^{i}}{\left(\eta^{i}+1\right)} .
$$

Jurisdiction $i$ 's transfer costs are then $\left(1-s^{i}\right) T^{i} P^{i}$, and maximizing the utility of its nonpoor satisfies the efficiency condition. ${ }^{12}$ The subsidy rate increases with $\eta^{i}$ and is proportional to $T^{j} / T^{i}$; the rate is thus higher for a 'poor' lowtransfer jurisdiction than for a high-transfer 'rich' one. ${ }^{13}$ The subsidy is, in a sense, symmetric: if jurisdiction $i$ is the 'rich' high-transfer jurisdiction, it still receives a subsidy from $j$, though $s^{i}<s^{j}$ if $T^{j}<T^{i}$ and $\eta^{i}=\eta^{j}$.

Finally, notice that $\partial P^{j} / \partial T^{i}$ refers to those migrants whose location changes with a small change in $T$, not to all migrants. Hence, a system of reimbursement like that of nineteenth-century England (where jurisdiction $i$ reimburses jurisdiction $j$ for all of $i$ 's poor who migrate to $j$ ) does not achieve efficient levels of transfers.

\footnotetext{
${ }^{12}$ Of course, if jurisdiction $i$ were offered a subsidy rate $s^{i}$ which depended explicitly on $T^{i}$, each nonpoor resident of jurisdiction $i$ would see $-T^{i} P^{i}\left(\mathrm{~d} s^{i} / \mathrm{d} T^{i}\right)$ as part of the price it faces, and a morc complicated subsidy rule would be nceded.

${ }^{13}$ It is possible that $s^{i}>1$. This would mean simply that if $T^{j} / T^{i}$ is large enough, it would pay jurisdiction $j$ to subsidize jurisdiction $i$ to push $T^{i}$ beyond the point where $\partial U_{\mathbf{N}}^{i} / \partial \widetilde{Y}_{\mathbf{P}}^{i}=0$.
} 
In a two-jurisdiction model, the appropriate subsidies could, in principle, be offered by each jurisdiction to the other without central government involvement. But with many jurisdictions, each has an incentive to be a freerider on the others' payments to jurisdiction $i$. We thus have a standard kind of public-goods problem with central government intervention needed to achieve an efficient outcome.

As we noted in the Introduction, there is a second line of argument for vesting a primary responsibility for poor relief with the central government: the claim that income levels of the poor are a national public good. In its strongest form, this argument would assert that individuals care equally about the well-being of the poor irrespective of their location. It is difficult, however, to find compelling empirical support for such a claim. Individuals contribute to national (and global) charities to assist the poor, but much (and perhaps most) of such giving has a largely local orientation. Our conjecture is that the appropriate way to characterize the utility functions of the nonpoor would involve, as arguments in these functions, weighted levels of income of the poor with heavier weights attached to the poor in one's own jurisdiction. However, in the absence of more compelling evidence in support of the national public-good argument, we are hesitant to put much reliance on it as a justification for a heavily centralized system of assistance to the poor.

There is, however, another normative argument for central involvement in poor relief that we find more persuasive. Returning to our earlier case of complete immobility of the poor, we recall that the equilibrium support level in our model represents the level of transfers for which we make no nonpoor individual better off without making another person worse off; it is the Pareto-efficient level of transfers for the group of nonpoor residents in the jurisdiction. Were we to take the well-being of the poor into consideration by, for example, the maximization of some social-welfare function that included the welfare of all the residents in the jurisdiction, we would presumably determine an optimal level of transfers that is greater than that based solely on the tastes of the nonpoor. From this perspective, we can argue that the equilibrium level of support in the immobility case is less than the socially optimal level; we might take it as a kind of lower bound for the optimal level of transfers. If we now introduce some degree of mobility of the poor, we are likely to get (as we found in the analysis) payment lcvels that are, on average, less than in the immobility case. This suggests a presumption that levels of assistance to the poor under a wholly decentralized system (at least in the absence of quite stringent residency requirements) will be suboptimal and points to the need for some form of central participation in poor relief. As the analysis indicated earlier, however, there is no guarantee that the movement from a decentralized to a wholly centralized system of support will result in increased levels of transfer payments - although there 
may be some reason (as our simulations suggest) to expect this as a likely outcome. As an alternative, one can argue for a system of matching grants by which means the central government would effectively reduce the 'price' of transfers in each local jurisdiction.

Finally, we would note another argument for a central role in assisting the poor based on a quite different kind of social value judgment. As we found in the first section of the paper, a decentralized equilibrium would involve varying levels of support for the poor with higher payment levels in jurisdictions where the poor are a relatively small fraction of the population. If we were to allow for varying incomes and tastes across jurisdictions, we would have a further source of variation in local levels of poor relief. While we might justify such variation in support levels on grounds of economic efficiency, there are other criteria for social justice that render such differentials in the treatment of the poor objectionable. Stigler (1957), for example, has voiced such an objection quite strongly; he argues that the redistribution $\therefore$ decision must be in some sense a national decision, for the proper amount of redistribution, even if rich and poor were chained to their communities [our emphasis], could not depend upon the accidents of income composition of a particular community' (p. 217). Some will take issue with Stigler on this matter, but as the argument suggests, the preferred intergovernmental structure for assisting the poor is not solely an economic matter. It will depend to some extent on various social values concerning, for example, the acceptability of substantial geographical variation in levels of support payments. ${ }^{14}$

Whatever one concludes concerning these supplementary arguments for a central role in poor relief, the analysis in this paper points to a basic source of inefficiency in decentralized systems stemming from the mobility of the poor. One mechanism to circumvent these distortions is to prohibit such migration, as was the case under the English Poor Laws. However, this really is not an option any longer in most countries. In the United States, for example, the U.S. Supreme Court has struck down residency requirements for assistance payments. But, more generally, there are compelling social and economic arguments for eliminating impediments to mobility. Migration of transfer recipients exists and must be taken into account in the design and implementation of assistance programs. And this suggests the need, strictly on grounds of economic efficiency, for central intervention to internalize the

\footnotetext{
${ }^{14}$ Gramlich (1985), for instance, has used his estimates of the U.S. welfare system to predict the response of support levels for the poor to sets of matching rates to internalize spillovers. His estimates suggest that preferences for support levels vary dramatically among the states such that even in the presence of a sensible matching system, payment levels would vary quite widely across the states. He finds these results sufficiently troubling on grounds of social justice to abandon such a scheme; he recommends instead a system with centrally mandated minimum levels of support. States would be free to supplement these national minima.
} 
externalities inherent in decentralized choice. As discussed earlier in this section, the pure economics of the matter suggests a system of matching grants to local jurisdictions to remedy the distortion.

\section{References}

Blank, Rebecca M., 1983, Welfare, wages and migration: An analysis of locational choice by female-headed households, unpublished paper.

Blaug, Mark, 1963, The myth of the old poor law and the making of the new, Journal of Economic History 23, 151-184.

Boadway, Robin W. and David E. Wildasin, 1984, Public sector economics, Second edition (Little, Brown and Co., Boston, MA).

Bradford, David F. and Wallace E. Oates, 1974, Suburban exploitation of central cities and governmental structure, in: Harold Hochman and George Peterson, eds., Redistribution through public choice (Columbia University Press, New York), 43-92.

Buchanan, James M., 1974. Who should distribute what in a Federal System? in: Harold Hochman and George Peterson, eds., Redistribution through public choice (Columbia University Press, New York), 22-42.

Cebula, Richard J., 1974, Interstate migration and the Tiebout hypothesis: An analysis according to race, sex, and age, Journal of the American Statistical Association, 876-879.

Ccbula, Richard J., Robert M. Kohn and Richard K. Vedder, 1973, Somc detcrminants of interstate migration of blacks, 1965-1970, Western Economic Journal 11, 500-505.

Cloward, R.A. and F.F. Piven, 1968, Migration, politics and welfare, Saturday Review, 31-35.

Curran, C., 1977, Migration and welfare: An analysis of their relationship, Industrial Journal of Economics, $1-16$.

Fraser, Derek, ed., 1976, The new poor law in the nineteenth century (St. Martin's Press, New Yorkl.

Gallaway, Lowell E., R.F. Gilbert and P.E. Smith, 1967, The economics of labor mobility: An empirical analysis, Western Economic Journal 5, 211-223.

Gramlich, Edward M., 1982, An econometric examination of the New Federalism, Brookings Papers on Economic Activity, 327-370.

Gramlich, Edward M., 1985, Reforming U.S. Fiscal Federalism arrangements, in: John Quigley and Daniel Rubinfeld, eds., American domestic priorities: An economic appraisal (University of California Press, Berkeley, CA), 34-69.

Gramlich, Edward M. and Deborah S. Laren, 1984, Migration and income redistribution responsibilities. Journal of Human Resources 19, 489-511.

Grewal, Bhajan and Russell Mathews, 1983, Federalism. locational surplus, and the redistributive role of subnational governments, unpublished paper.

Kaun, David E., 1970, Negro migration and unemployment, Journal of Human Resources 5 , $191-207$.

Kumar, Rishi, 1977, More on non-white migration, welfare levels, and the political process, Public choice 32, 151-154.

Ladd, Helen F. and Fred C. Doolittle, 1982, Which level of government should assist the poor?, National Tax Journal 35, 323-336.

Marshall, J.D., 1968, The old poor law, 1795-1834 (Macmillan, London).

Oates, Wallace E., 1972, Fiscal Federalism (Harcourt, Brace, Jovanovich, New York).

Oates, Wallace E., 1977, An economist's perspective on Fiscal Federalism, in: W. Oates, ed., The political economy of Fiscal Federalism (Heath-Lexington, MA), 3-20.

Orr. Larry L., 1976. Income transfers as a public good: An application to AFDC, American Economic Review 66, 359-371.

Pauly, Mark V., 1973, Income redistribution as a local public good, Journal of Public Economics 2, 35-58.

Peltzman, Salı, 1980, The growth of government, Journal of Law and Economics 23, 209-287.

Southwick, Lawrence, 1981, Public welfare programs and recipient migration, Growth and Change $12,22-32$. 
Stigler, George, 1957, The tenable range of functions of local government, in: Joint economic committee, U.S. Congress, Federal expenditure policy for economic growth and stability (U.S. Government Printing Office, Washington, DC), 213-219.

Tate, William E., 1969, The parish chest (Cambridge University Press, London).

Tiebout, Charles, 1956, A pure theory of local expenditures, Journal of Political Fconomy 64, 416-424.

Tresch, Richard W., 1981, Public finance: A normative theory (Business Publications, Plano, Texas).

U.S. Bureau of the Census, 1985, Money income of households, families, and persons in the United States: 1983, Current population reports, Series P-60, No. 146.

Varian, Hal R., 1980, Redistributive taxation as social insurance, Journal of Public Economics $14,49-68$. 